\title{
Bacterial communities in the rumen of Holstein heifers differ when fed orchardgrass as pasture vs. hay
}

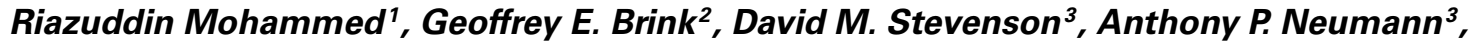 \\ Karen A. Beauchemin ${ }^{1}$, Garret Suen ${ }^{3}$ and Paul J. Weimer ${ }^{2,3 *}$ \\ ${ }^{1}$ Lethbridge Research Center, Agriculture and Agri-Food Canada, Lethbridge, AB, Canada \\ 2 US Department of Agriculture, United States Dairy Forage Research Center, Agricultural Research Service, Madison, WI, USA \\ ${ }^{3}$ Department of Bacteriology, University of Wisconsin, Madison, WI, USA
}

Edited by:

Emilio M. Ungerfeld, Instituto de Investigaciones Agropecuarias INIA -

Carillanca, Chile

Reviewed by:

Carl James Yeoman, Montana State University, USA

Gemma Henderson, AgResearch

Ltd., New Zealand

Charles James Newbold

Aberystwyth University, UK

*Correspondence:

Paul J. Weimer, US Department of Agriculture, United States Dairy

Forage Research Center, Agricultural

Research Service, 1925 Linden

Drive West, Madison, WI 53706,

USA

e-mail:paul.weimer@ars.usda.gov
The rich and diverse microbiota of the rumen provides ruminant animals the capacity to utilize highly fibrous feedstuffs as their energy source, but there is surprisingly little information on the composition of the microbiome of ruminants fed all-forage diets, despite the importance of such agricultural production systems worldwide. In three 28-day periods, three ruminally-cannulated Holstein heifers sequentially grazed orchardgrass pasture (OP), then were fed orchardgrass hay $(\mathrm{OH})$, then returned to OP. These heifers displayed greater shifts in ruminal bacterial community composition (determined by automated ribosomal intergenic spacer analysis and by pyrotag sequencing of 16S rRNA genes) than did two other heifers maintained $84 \mathrm{~d}$ on the same OP. Phyla Firmicutes and Bacteroidetes dominated all ruminal samples, and quantitative PCR indicated that members of the genus Prevotella averaged $23 \%$ of the $16 \mathrm{~S}$ rRNA gene copies, well below levels previously reported with cows fed total mixed rations. Differences in bacterial community composition and ruminal volatile fatty acid (VFA) profiles were observed between the $\mathrm{OP}$ and $\mathrm{OH}$ despite similarities in gross chemical composition. Compared to $\mathrm{OP}$, feeding $\mathrm{OH}$ increased the molar proportion of ruminal acetate $(P=0.02)$ and decreased the proportion of ruminal butyrate $(P<0.01)$, branched-chain VFA $(P<0.01)$ and the relative population size of the abundant genus Butyrivibrio $(P<0.001)$, as determined by pyrotag sequencing. Despite the low numbers of animals examined, the observed changes in VFA profile in the rumens of heifers on OP vs. OH are consistent with the shifts in Butyrivibrio abundance and its known physiology as a butyrate producer that ferments both carbohydrates and proteins.

Keywords: rumen microbiology, bacterial community composition, pasture, hay, forage, volatile fatty acids

\section{INTRODUCTION}

Ruminal microbes, particularly bacteria, perform a multitude of functions in the process of digesting dietary organic matter (Russell, 2002). They play an essential role in fermenting simple and complex carbohydrates into volatile fatty acids (VFA); in the biohydrogenation of polyunsaturated fatty acids; and in the degradation of dietary protein and partial recapture of nonprotein nitrogen as microbial cell protein for subsequent protein nutrition of the animal. It is well known that ruminal bacterial communities respond to changes in diet and environmental conditions (Dehority and Orpin, 1997; Dehority, 2003) and also exhibit host specificity (Weimer et al., 2010a). Most of the studies that have examined the influence of diet on ruminal bacterial communities have employed total mixed rations (TMR) containing various proportions of forage and concentrates such as cereal grains (Boeckaert et al., 2008; Kim et al., 2008; Pitta et al., 2014). Few studies have compared ruminal bacterial communities on all-forage diets, despite the fact that much of the world's ruminant production is based on such diets. In particular, there are no reports to our knowledge that have compared ruminal bacterial communities between animals fed fresh vs. conserved forages (hay or silage) in forage-only diets.

This study was initiated to examine the effect of feeding Holstein heifers orchardgrass pasture (OP) or orchardgrass hay $(\mathrm{OH})$ on ruminal bacterial community composition (BCC) characterized by automated ribosomal intergenic spacer analysis (ARISA) to compare whole communities, and by pyrotag sequencing of $16 \mathrm{~S}$ rRNA genes to make more specific comparisons at the phylum and genus levels. Heifers were used rather than lactating cows because the distance of our grazing plots from our milking parlor $(\sim 3 \mathrm{~km}$, across a state highway) precluded incorporation of a lactation study. Because the study was conducted over the summer months when quality of orchardgrass and other cool-season grasses in the upper Midwestern USA varies substantially (Brink and Casler, 2012; Brink et al., 2013), an experimental design was selected in which one group of 3 heifers was alternately grazed $\mathrm{OP}$ (period 1), then fed $\mathrm{OH}$ harvested from the same field at the same growth stage (period 2), then returned to OP (period 3). For comparison, a group of 2 heifers was maintained on OP for all 3 periods. Each period was $28 \mathrm{~d}$ in 
length. Based on expected changes in chemical composition for forage during harvest and preservation as hay, we hypothesized that BCC would differ among heifers grazing OP compared with those fed $\mathrm{OH}$, and that these differences would be associated with differences in forage composition and/or differences in the profiles of primary fermentation products (VFA ratios) in ruminal fluid.

\section{MATERIALS AND METHODS PASTURE AND HAY FEEDING OF HEIFERS}

Experiments were conducted during June-August 2009 at the US Dairy Forage Research Center Farm near Prairie du Sac, WI, USA $\left(43^{\circ} 20^{\prime} 24^{\prime \prime} \mathrm{N}-89^{\circ} 43^{\prime} 12^{\prime \prime} \mathrm{W}\right)$, in strict accordance with the recommendations in the Guide for the Care and Use of Laboratory Animals of the National Institutes of Health, under research protocol A01427 approved by the University of WisconsinMadison College of Agricultural and Life Sciences Animal Care and Use Committee. Ruminal cannulations were performed under a separate protocol (A01307) by a licensed University of Wisconsin veterinarian, using lidocaine anesthetic to minimize animal discomfort. Five ruminally cannulated Holstein heifers (mean age $17 \pm 0.89$ mo; mean BW $465 \pm 14 \mathrm{~kg}$ ) were fed orchardgrass (Dactylis glomerata cv "Bronc") as either pasture (OP) or hay $(\mathrm{OH})$. Of the 5 heifers, 3 were offered OP, $\mathrm{OH}$, and $\mathrm{OP}$ during the 1st, 2nd, and $3 \mathrm{rd}$ periods, respectively, while the other 2 heifers remained on OP in all three periods. This experimental design was chosen because quality and composition of cool-season grasses such as orchardgrass varies dramatically during the summer in the upper Midwestern USA (Brink et al., 2013), making a switchback design inappropriate. Alternative designs involving a comparison of groups of animals fed only pasture vs. those fed only hay were rejected because they would not allow detection of diet-dependent shifts in BCC or in ruminal chemistry within individual animals.

The duration of each experimental period was 28 days. During each period, two pastures of 0.6 and 0.4 ha were each subdivided into 0.1 ha paddocks. Beginning with the paddock having the grass at v2-v4 stage (residual sward height of $10 \mathrm{~cm}$; Moore et al., 1991) heifers grazed for 2 days before being moved to the next paddock. Heifers returned to the first paddock after completing one rotation of all the paddocks. Pasture herbage allowance was at least three times the anticipated dry matter (DM) intake per animal $\left(11 \mathrm{~kg} \mathrm{DM} \mathrm{d}^{-1}\right)$. For making $\mathrm{OH}$, orchardgrass was harvested at the same maturity stage from a paddock adjacent to the grazing pastures. The grass was wilted for $48 \mathrm{~h}$ after cutting, raked, and further dried to $20 \%$ moisture over $24 \mathrm{~h}$ before being baled in small square bales (approximately $20 \mathrm{~kg}$ each). OH was fed ad libitum from racks in an unvegetated corral adjacent to the pasture plots. All heifers had access to water and were kept outdoors for the entire period of the study.

Specific measurements of intake or animal movement were not made, but the combination of probably low intakes by young, non-lactating animals and lush pasture growth allowed us to use small paddocks. The resulting limited movement of the animals probably did not result in significant differences in energy expenditure among the two dietary groups.

\section{FORAGE ANALYSIS}

The pastures grazed by the heifers were sampled by clipping the grass from three randomly-placed quadrats (metal squares $25 \times 100 \mathrm{~cm}$ ) to a $10-\mathrm{cm}$ residual sward height and then dried at $55^{\circ} \mathrm{C}$. The forage sample representing each period was a composite of grass samples collected from each paddock grazed within a rotation. Although the OP samples were dried relatively rapidly in a forced-air oven, minor changes in nutrient composition due to plant cellular respiration may have occurred within the first few hours. Duplicate samples of dried OP and $\mathrm{OH}$ were ground through a $1-\mathrm{mm}$ screen of a Wiley mill, and were analyzed for crude protein (CP; Leco FP-2000 A nitrogen analyzer, Leco Corp., St. Joseph, MI), neutral detergent fiber (NDF; using the procedure of Mertens, 2002 to include both $\alpha$-amylase and sodium sulfite during refluxing), as well as acid detergent fiber (ADF) and acid detergent lignin (Van Soest et al., 1991). Water-soluble carbohydrates (WSC) were determined by colorimetric analysis of aqueous extracts. In brief, $1 \mathrm{~g}$ of oven-dried $\left(55^{\circ} \mathrm{C}\right)$ forage sample was suspended in $40 \mathrm{~mL}$ of deionized water (pre-warmed to $39^{\circ} \mathrm{C}$ ) and shaken in a reciprocal shaker $\left(120\right.$ cycles $\left.\min ^{-1}\right)$ for $60 \mathrm{~min}$ in a room maintained at $39^{\circ} \mathrm{C}$. The aqueous extracts were then centrifuged at $10,000 \times \mathrm{g}$ for $5 \mathrm{~min}$ at room temperature, and a subsample of the supernatant $(25 \mu \mathrm{L})$ was analyzed in duplicate by the phenol-sulfuric acid method (Dubois et al., 1956), using glucose as standard.

\section{RUMINAL SAMPLES AND PROCESSING}

Ruminal digesta were collected at $\sim 13: 00 \mathrm{~h}$ on 3 consecutive days of each period (days 26-28) by spot sampling from the midpoint along the length of the ruminal contents and from the midpoint along the height of the ruminal contents (ventral rumen). Prior to sampling, ruminal $\mathrm{pH}$ was measured by direct insertion into the rumen of a $\mathrm{pH}$ probe connected to a model 340i portable pH meter (WTW, Weinheim, Germany) subjected to a 2-point calibration ( $\mathrm{pH} 4.01$ and 7.00) just prior to use. At the time of collection, ruminal digesta were tightly hand-squeezed through 4 layers of cheesecloth, to separate the solid (SO) and liquid (L) phases. Volatile fatty acids (VFA) were determined from the L phase of ruminal digesta by HPLC (Weimer et al., 1991).

\section{MICROBIAL DNA ISOLATION}

Microbial DNA was extracted from the L phase directly, but the SO phase was first homogenized in a blender with chilled extraction buffer ( $100 \mathrm{mM}$ Tris/ $\mathrm{HCl}, 10 \mathrm{mM}$ EDTA, $0.15 \mathrm{M} \mathrm{NaCl}$ $\mathrm{pH}$ 8.0) to release the solids-associated bacteria as described by Stevenson and Weimer (2007). In brief, DNA was extracted from $25 \mathrm{~mL}$ of L phase and $25 \mathrm{~g}$ of SO phase of ruminal digesta using a series of wash steps with the extraction buffer followed by lysis of the microbial cells in a bead-beater, extraction with combinations of phenol/chloroform and precipitation with isopropanol (Stevenson and Weimer, 2007). The method is essentially identical to the PCSA method of Henderson et al. (2013) that has been shown to give very high yields of DNA that is likely to be most representative of the ruminal microbial community. The DNA obtained was resuspended in TE $(10 \mathrm{mM}$ Tris $\mathrm{HCl}, 1 \mathrm{mM}$ EDTA, $\mathrm{pH}$ 8.0) and purified using an Electro-Eluter (C.B.S Scientific Company, Del Mar, CA). 


\section{ARISA}

The internally transcribed region (ITS) between the bacterial $16 \mathrm{~S}$ and $23 \mathrm{~S}$ rRNA genes was amplified using domain-specific bacterial primers ITSF (5'-GTCGTAACAAGGTAGCCGTA-3') and ITSReub ( $5^{\prime}$-GCCAAGGCATCCAAC- $\left.3^{\prime}\right)$. The primer ends were complementary to the respective positions 1423 and 1443 of the $23 \mathrm{~S}$ rRNA and positions 38 and 23 of the 16S rRNA of Escherichia coli (Cardinale et al., 2004). The PCR components and the cycling conditions have been described previously (Weimer et al., 2010b). The PCR product obtained was resolved in a Beckman Coulter CEQ8000 Genetic Analysis System using the run parameters as described by Weimer et al. (2010b). In brief, $0.5 \mu \mathrm{L}$ of the PCR product was mixed with $1 \mu \mathrm{L}$ of Beckman Coulter WelRed \#1 infrared fluorescent dye-labeled DNA standard ladder (MapMarker 1000, Bio Ventures, Murfreesboro, TN) and $39 \mu \mathrm{L}$ of sample loading solution (Beckman Coulter) and loaded into microtiter plates. Capillary electrophoresis was conducted following the manufacturer's instructions after covering the liquid surface of the wells with molecular biology grade mineral oil.

The raw data obtained from capillary electrophoresis were imported into GeneMarker software (v. 1.75, Soft Genetics LLC, State College, PA) for further analysis. Peak detection and quantification was performed using the settings for amplicon fragment length polymorphism analysis described in the GeneMarker manual. Peak sizes (bp) were determined using the DNA standard ladder described above. Baseline subtraction and peak smoothing was performed as described in the GeneMarker manual. The panel generated by the software was screened manually to remove any questionable peaks caused by pull-up from the dyed DNA standard. All peaks corresponding to AL > 112bp were exported for correspondence analysis (described under the Statistical Analysis Section).

\section{LIBRARY PREPARATION AND 454 PYROSEQUENCING}

Based on similarities in BCC of the 3 consecutive daily samplings within heifer X period, as revealed by ARISA (see Results), DNA samples from each separate ruminal fraction ( $\mathrm{L}$ or $\mathrm{SO}$ ) from the 3 consecutive daily samplings from each heifer were pooled in equimolar proportions, resulting in a total of 30 samples. L and SO samples corresponding to one sampling day during period one from heifer 3292 were not included in the analysis as this sampling was deemed to be an outlier (see Statistical Analyses, below). Amplification was achieved using custom designed primers containing the Roche $454 \mathrm{~A}$ or B Titanium sequencing adaptors on the forward primer, 926F-5'-CCTATCCCCTGT GTGCCTTGGCAGTCTCAGAAACTYAAAKGAATTGACGG -3', and one of 30 unique barcodes, $5 \mathrm{bp}$ in length, as indicated by XXXXX in the reverse primer, 1392R-5'-CCATCTCATCCCTG CGTGTCTCCGACTCAG - XXXXX-ACGGGCGGTGTGTRC-3'. Five $20 \mu \mathrm{l}$ PCR reactions, which included $10 \mathrm{ng}$ of template DNA, $0.5 \mu \mathrm{M}$ of each primer, and $18 \mu \mathrm{L}$ high-fidelity DNA polymerase Platinum Blue master mix (Invitrogen by Life Technologies, Grand Island, NY) were performed for each sample. PCR conditions consisted of an initial denaturation at $94^{\circ} \mathrm{C}$ for $2 \mathrm{~min}$ followed by 30 cycles of $94^{\circ} \mathrm{C}$ for $30 \mathrm{~s}, 50^{\circ} \mathrm{C}$ for $45 \mathrm{~s}$, and $68^{\circ} \mathrm{C}$ for $105 \mathrm{~s}$, with a final extension at $68^{\circ} \mathrm{C}$ for $10 \mathrm{~min}$. Products from the five reactions were pooled, purified, and concentrated to $50 \mu \mathrm{L}$ using the PureLink ${ }^{\mathrm{TM}}$ Quick PCR Purification Kit (Invitrogen by Life Technologies). One last purification step was performed by excising the appropriately sized amplicon $(\sim 550 \mathrm{bp})$ from a $1 \%$ low-melt agarose gel after electrophoresis, followed by recovery using the Zymoclean ${ }^{\mathrm{TM}}$ Gel DNA Recovery Kit (Zymo Research Corp., Irvine, CA). Each sample was quantified using a Qubit ${ }^{\circledR}$ Fluorometer (Invitrogen, San Diego, CA), and pooled at an equimolar ratio to create a single library at $1 \times 10^{9}$ molecules per $\mu \mathrm{L}$. The library was subsequently diluted to a concentration of $1 \times 10^{6}$ molecules per $\mu \mathrm{L}$ and used as template for emPCR at a ratio of 0.8 molecules per DNA capture bead. Bead recovery and sequencing were performed following the manufacturer's guidelines for a Roche 454 GS Junior pyrosequencer with the Lib-L kit and Titanium chemistry (Roche Applied Science, Indianapolis, IN).

\section{qPCR PRIMERS}

The primers used for qPCR have been described previously (Stevenson and Weimer, 2007) and their currently known specificities were determined by in silico re-analysis in Genbank. The genus Prevotella forward primer (PreGen4F 5'-GGT TCT GAG AGG AAG GTC CCC-3') matched over 100 Prevotella sequences plus 11 species representing other genera, but no Alloprevotella; the reverse primer (PreGen4R 5'-TCC TGC ACG CTA CTT GGC TG-3') matched only Prevotella sequences and one Alloprevotella sequence, but none of the 11 non-Prevotella sequences that matched the forward primer. The M. elsdenii forward primer (MegEls2F 5'-AGA TGG GGA CAA CAG CTG GA-3') matched only this species and one Anaeroglobus species, but the MegEls2R 5'-CGA AAG CTC CGA AGA GCC T-3') primer matched only M. elsdenii. The B. fibrisolvens primers displayed less specificity, reflecting the considerable taxonomic uncertainty of $B$. fibrisolvens (Willems and Collins, 2009). Among strains identified at the family level or below, and excluding taxonomically unassigned sequences, the forward primer (ButFib2F 5'-ACC GCA TAA GCG CAC GGA-3') matched 8 non-Butyrivibrio species within the Lachnospiraceae and Clostridiaceae, while the reverse primer (ButFib2R 5'-CGG GTC CAT CTT GTA CCG ATA AAT$3^{\prime}$ ) matched 7 strains of Pseudobutyrivibrio. However, only one non-Butyrivibrio strain, Pseudobutyrivibrio ruminis Ce1, matched both the forward and reverse primers. Consequently we refer to the assemblage identified by the Butyrivibrio primers as the "Butyrivibrio fibrisolvens group" to indicate that the primers, though representative of a large number of $B$. fibrisolvens strains, were not completely monospecific.

\section{qPCR}

Quantitative real time ( $\mathrm{qRT}$ )-PCR assays for specific bacterial taxa were conducted with the $\mathrm{L}$ phase of ruminal digesta, using the primers described above. The standards for M. elsdenii, B. fibrisolvens group, and genus Prevotella assay were prepared by making a serial dilution of the genomic DNA from a pure culture of the strains T81, H17c, and P. brevis GA33, respectively. The standards and the set of samples belonging to each period were run in the same plate in triplicate. The relative population size (RPS) of the target bacterium was determined as the ratio of the amplification of target taxon 16S rRNA copy numbers to the amplification 
of the background obtained by amplifying the 16S rRNA gene with bacterial primers (BAC338F and BAC805R, Yu et al., 2005). The qRT-PCR was conducted using POWER SYBR Green PCR Master Mix (Applied Biosystems, Warrington, UK), forward and reverse primers (25 pmol of each primer/reaction) and approximately $20 \mathrm{ng}$ of template DNA in a final volume of $25 \mu \mathrm{L}$ per reaction. Quantitative real time-PCR assays were conducted using Applied Biosystems Prism 7300 sequence detection system. The amplification conditions were 40 cycles of $95^{\circ} \mathrm{C}$ for $15 \mathrm{~s}$ and an annealing and extension period of $60 \mathrm{~s} \mathrm{(at} 59^{\circ} \mathrm{C}$ for M. elsdenii, $60^{\circ} \mathrm{C}$ for $\mathrm{B}$. fibrisolvens, and $60^{\circ} \mathrm{C}$ for Prevotella). The efficiency of the PCR was calculated as the negative reciprocal of the slope of the line obtained by plotting Ct vs. $\log$ DNA concentrations of the standard dilution series.

\section{STATISTICAL ANALYSIS}

For ARISA, the data matrix resulting from the export of peak areas from GeneMarker was analyzed by correspondence analysis following the method of Ludwig and Reynolds (1988) using custom software written in the $\mathrm{C}$ programming language. One ordination point (out of 90 total) corresponding to the L phase of one heifer in the first period was identified as an outlier (geometric distance from the origin 6.4 times that of the next most distant point from the origin). This sample together with the corresponding sample in the SO phase was excluded from the analysis. The ordination points for the first 2 components of the correspondence analysis were plotted as scatter plots. The relative peak areas obtained from ARISA were analyzed for the shifts in BCC using analysis of similarity (ANOSIM; Clarke, 1993). Four data matrices were constructed from the ARISA data (L and SO phases for both $\mathrm{OP}$ and $\mathrm{OH}$ diets) corresponding to each heifer. Each data matrix contained 281 rows (corresponding to the different amplicon lengths, AL) and 9 columns ( 3 daily samples for each of the 3 periods).

For pyrosequencing, the sequence processing and data analysis was performed using the program mothur v.1.33.3 (Schloss et al., 2009) with default command parameters, unless specified. Flowgrams were trimmed to 450 flows and de-noised using the shhh.flows command, the mothur implementation of the AmpliconNoise algorithm (Quince et al., 2011). The resulting sequences were trimmed (pdiffs $=2$, bdiffs $=0$, maxhomop $=6$, minlength $=250$ ) followed by alignment against the SILVA 16S rRNA gene reference alignment database (Pruesse et al., 2007). Chimera detection was performed using the chimera.uchime command (http://drive5.com/uchime) on a screened version of the alignment (filter.seqs) that had been reduced using unique.seqs and pre.cluster (diffs $=2$ ). The cluster command was used to assign sequences to operational taxonomic units (OTUs) using the nearest neighbor algorithm. All subsequent OTU-based analyses were performed using a cutoff of 0.03. Classification of OTUs was achieved using the Greengenes database (DeSantis et al., 2006) with a confidence level of at least 80 percent. Sequences classified as either domain Eukaryota or domain Archaea were removed from all subsequent analyses. Comparisons of taxa relative abundances among the 4 groups (OP/L, OP/SO, OH/L, OH/SO, encompassing the two forage types $\mathrm{OH}$ and $\mathrm{OP}$ and the two ruminal phases $\mathrm{L}$ and $\mathrm{SO}$ ) were normalized by subsampling to 1856 sequences, the size of the smallest group. Diversity and coverage metrics were obtained using the command summary.single (calc = sobs-chao-ace-jackbergerparker-shannon-simpson-coverage,label $=0.03$, subsample $=\mathrm{T}$ ). Analysis of community similarities (ANOSIM) (Clarke, 1993) was performed using the anosim command. The command tree.shared $($ calc $=$ braycurtis,label $=0.03$, subsample $=\mathrm{T}$ ) using unweighted pair group method with arithmetic mean (UPGMA) clustering was performed to construct the dendrogram showing the relationships among the bacterial communities. Weighted UniFrac (Lozupone and Knight, 2005) was performed on the tree generated from the clearcut command using the command unifrac.weighted (subsample $=\mathrm{T}$ ).

Ruminal fermentation variables and the RPS of $B$. fibrisolvens and M. elsdenii in L phase of ruminal digesta, as determined by qPCR, were averaged per heifer per period and analyzed using the MIXED procedure of SAS v.9.4 (SAS, Cary, NC). Heifer within diet was the experimental unit with diet and period designated as fixed effects in the model. Least square means (LSM) for diet and heifer within diet were determined and declared significant when $P<0.05$. Differences in the LSM were determined using ADJUST $=$ Tukey option in the LSM statement. Correlations between microbial taxa and the mol fraction or millimolar concentrations of individual VFA were determined using the CORR procedure in SAS.

\section{ACCESSION NUMBERS}

Raw sequence files for each of the 30 samples analyzed by 454 pyrosequencing have been deposited at the National Center for Biotechnological Information (NCBI) Short Read Archive and can be found under project accession PRJNA253331.

\section{RESULTS}

\section{NUTRIENT COMPOSITION OF FORAGES}

Nutrient composition of the forages is presented on a dry matter basis in Table 1. Overall the OP averaged across periods had a higher WSC and CP, and lower NDF and ADF contents than did the $\mathrm{OH}$. However, direct comparison of $\mathrm{OP}$ and $\mathrm{OH}$ harvested during period 2 revealed no difference in $\mathrm{CP}, \mathrm{NDF}, \mathrm{ADF}, \mathrm{ADL}$, or ash content (all $P>0.6$ ); WSC was numerically higher in $\mathrm{OH}$ than in $\mathrm{OP}$, but the difference was not significant $(P=0.16)$.

\section{RUMINAL VFA}

Ruminal $\mathrm{pH}$ was not influenced by forage source $(P=0.40$, Table 2). Total VFA concentration was greater for $\mathrm{OH}$ than for $\mathrm{OP}$ $(P=0.02)$. In addition, there were substantial differences in the molar proportions of the ruminal VFA. The proportion of acetate was greater for $\mathrm{OH}$ than for $\mathrm{OP}(P=0.02)$ and the proportion of valerate tended to be greater for $\mathrm{OH}$ than $\mathrm{OP}(P=0.05)$. The molar proportions of butyrate $(P<0.01)$, isobutyrate $(P<$ $0.01)$ and the co-eluting pair isovalerate +2 -methylbutyrate $(P<$ $0.01)$ were greater for $\mathrm{OP}$ than for $\mathrm{OH}$. Variation in the molar proportions of acetate and butyrate in individual animals across the periods is plotted in Figure 1. All 3 heifers subjected to dietary change (3274, 3292, and 3295) displayed increased molar proportions of acetate (Figure 1A) and decreased proportions of butyrate (Figure 1B) upon switch from $\mathrm{OP}$ to $\mathrm{OH}$, and a return to 
Table 1 | Nutrient compositions of orchardgrass used in this study ${ }^{a}$.

\begin{tabular}{|c|c|c|c|c|}
\hline & \multicolumn{3}{|c|}{ Pasture } & \multirow{2}{*}{$\frac{\text { Hay }^{\mathbf{b}}}{\text { Period } 2}$} \\
\hline & Period 1 & Period 2 & Period 3 & \\
\hline Crude protein & $11.8 \pm 0.10$ & $13.3 \pm 0.08$ & $23.5 \pm 0.04$ & $13.3 \pm 0.12$ \\
\hline $\begin{array}{l}\text { Water-soluble } \\
\text { carbohydrate }\end{array}$ & $9.66 \pm 2.95$ & $4.54 \pm 0.26$ & $8.90 \pm 1.00$ & $6.28 \pm 0.89$ \\
\hline $\begin{array}{l}\text { Neutral } \\
\text { detergent fiber }\end{array}$ & $55.3 \pm 0.46$ & $63.1 \pm 0.01$ & $50.7 \pm 0.07$ & $62.7 \pm 0.57$ \\
\hline $\begin{array}{l}\text { Acid detergent } \\
\text { fiber }\end{array}$ & $28.8 \pm 0.54$ & $34.0 \pm 0.52$ & $25.0 \pm 0.13$ & $33.1 \pm 0.25$ \\
\hline $\begin{array}{l}\text { Acid detergent } \\
\text { lignin }\end{array}$ & $3.63 \pm 0.15$ & $3.56 \pm 0.64$ & $3.04 \pm 0.43$ & $3.66 \pm 0.06$ \\
\hline Ash & $2.16 \pm 0.46$ & $1.27 \pm 0.64$ & $1.48 \pm 0.05$ & $1.23 \pm 0.59$ \\
\hline
\end{tabular}

${ }^{a}$ Data are mean values $\pm S D$ from duplicate samples, expressed on a percent dry matter basis.

${ }^{b}$ Hay was prepared from orchardgrass grown for 21 days of growth, to the same growth stage (vegetative) that pasture was grazed. The hay was stored under cover until the $\mathrm{OH}$ stage began (day 24 of the pasture period).

Table 2 | Least-square means of ruminal fermentation variables in heifers grazing orchardgrass pasture (OP) or consuming orchardgrass hay $(\mathrm{OH})^{\mathrm{a}}$.

\begin{tabular}{lcccc}
\hline Variable $^{\mathbf{b}}$ & \multicolumn{4}{c}{ Diet } \\
\cline { 2 - 5 } & OH & OP & s.e.m. & $\boldsymbol{P}^{\text {-value }} \mathbf{d}^{\mathbf{d}}$ \\
\hline & & & & \\
Ruminal pH & 6.35 & 6.26 & 0.07 & 0.40 \\
Total VFA (mM) & 182.2 & 132.7 & 11.1 & 0.02 \\
VFA mol (100 mol) & & & & \\
Acetate & 72.2 & 68.9 & 0.75 & 0.02 \\
Propionate & 17.1 & 16.6 & 0.49 & 0.49 \\
Butyrate & 7.73 & 10.1 & 0.32 & $<0.01$ \\
Isobutyrate & 0.78 & 1.35 & 0.07 & $<0.01$ \\
Valerate & 1.29 & 1.11 & 0.05 & 0.05 \\
Isovalerate + 2-methylbutyrate & 0.91 & 1.90 & 0.13 & $<0.01$ \\
& & & &
\end{tabular}

${ }^{a}$ Hay was harvested after 21 days of growth of orchardgrass at the same growth stage (vegetative) that pasture was grazed.

${ }^{b}$ VFA $=$ volatile fatty acid.

${ }^{c}$ Co-eluted on HPLC analysis.

${ }^{d}$ Comparison across all heifers.

the original proportions upon a return to OP. By contrast, the two heifers maintained on OP (3298 and 3412) showed no changes in the proportions of these VFA across periods (Figures 1A,B).

\section{BACTERIAL COMMUNITY COMPOSITION}

Shifts in BCC across period were first examined using ARISA. The number of discrete amplicon lengths (AL) detected across all samples by the analysis of raw data generated from capillary electrophoresis of PCR products was 281, spanning a range of 61-798 bp. The mean number of AL detected in individual samples was 113 (minimum $=44$, maximum $=159$ ). The mean number of $\mathrm{AL}$ detected in the SO digesta were greater than $\mathrm{L}$ digesta (least-square means (LSM) of 118.3 for SO and 106.8 for L; S.E.D. $=3.47, P=0.021)$. The mean number of amplicons did not differ between forage form for the SO digesta (LSM $=120.0$ for $\mathrm{OH}$ vs. 116.6 for OP; S.E.D. $=6.7, P=0.614$ ), or for the $\mathrm{L}$ digesta $(\mathrm{LSM}=101.4$ for $\mathrm{OH}$ and 112.2 for OP; S.E.D. $=$ 7.47, $P=0.141)$. Correspondence analysis of the ARISA profile across the entire data set revealed that the first 2 components contributed $4.1 \%$ and $3.5 \%$, respectively, to the total variation in the profile. These low percentages are consistent with the high dimensionality of the data (i.e., 113 different AL in a sample would provide 113 dimensions for analysis).

The ordination points from correspondence analysis of the ARISA profiles are shown Figure S1. For the 3 heifers (3274, 3292, and 3295) that were subjected to the $\mathrm{OH}$ treatment (i.e., the dietary sequence pasture/hay/pasture), the ordination points corresponding to the $\mathrm{OH}$ diet clustered separately from those on OP. It should be noted that the ordination points corresponding to $\mathrm{OP}$ in the third period (following transition from $\mathrm{OH}$ to $\mathrm{OP}$ ) were close to those of OP in the first period (communities before changing to $\mathrm{OH}$ diet) and were generally well separated from those of $\mathrm{OH}$, suggesting a return to a BCC similar to that present before the dietary switch. The ordination points corresponding to heifers 3298 and 3412, which remained on OP throughout the periods, were more closely clustered, indicating smaller changes in BCC over the course of the experiment. Analysis of similarity (ANOSIM) on the ARISA data revealed that the L and SO communities differed $(R=0.179, P=0.005)$. Differences between $\mathrm{OP}$ and $\mathrm{OH}$ communities, taken as a whole, were confounded by the large differences in the L and SO communities. However, ANOSIM conducted within heifer and phase revealed that of OP vs. $\mathrm{OH}$ communities differed (Figure $\mathrm{S} 1$ ). For each heifer $\mathrm{x}$ period combination, the ordination points for the three successive ruminal sampling days within period were closely spaced, indicating that BCC had stabilized by the end of each period.

In order to provide more phylogenetic information on BCC, the isolated DNA was subjected to 16S rRNA gene sequencing using 454 pyrotag sequencing. Three successive daily samples within each heifer $\times$ period combination (which as noted above were highly similar from ARISA) were pooled to reduce sample number from 90 to 30 . A total of 94,224 sequences were obtained, with an average per pooled sample of 3141 sequences. The pooled samples contained an average of 233 unique OTUs (range 169305 ), and Good's coverage values (Good, 1953) of $\geq 0.92$ (Table $\mathrm{S} 1$ ). The shifts in BCC revealed by ARISA were generally confirmed by pyrotag sequencing data. In principal component analysis, linear distances between points representing each feeding period were smaller for each heifer on the OP treatment than on the $\mathrm{OH}$ treatment (Figure 2). Moreover, within each of the 3 heifers subjected to dietary shift, the linear distance between the points corresponding to the two OP periods were much smaller than the distances between the points corresponding to OP vs. $\mathrm{OH}$, suggesting a return to a similar BCC following a return to OP. Bray-Curtis analysis (Figure 3 ) revealed that individual communities displayed strong groupings primarily by rumen digesta phase ( $\mathrm{SO}$ vs. L), and secondarily by forage source (OP vs. $\mathrm{OH}$ ). ANOSIM (Table S2) confirmed that the communities associated with the $\mathrm{L}$ and SO fractions were dissimilar $(P<0.001)$, as 


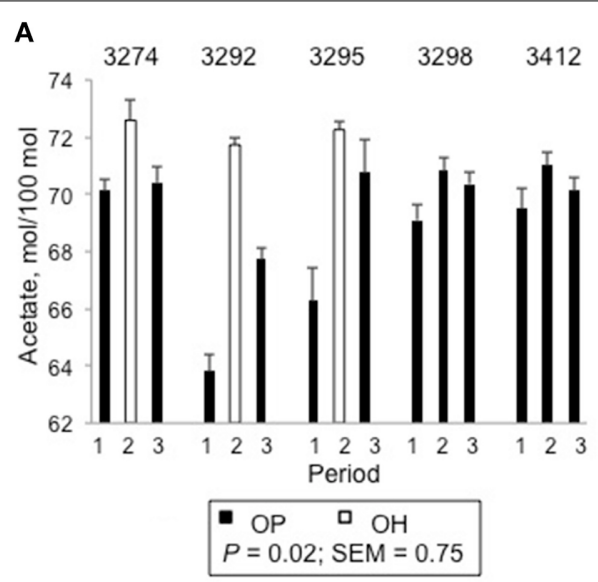

FIGURE 1 | Molar percentages of ruminal acetate $(A)$ and butyrate (B) in individual heifers across periods. Diets were orchardgrass pasture $(\mathrm{OP})$ and orchardgrass hay $(\mathrm{OH})$ harvested from at the

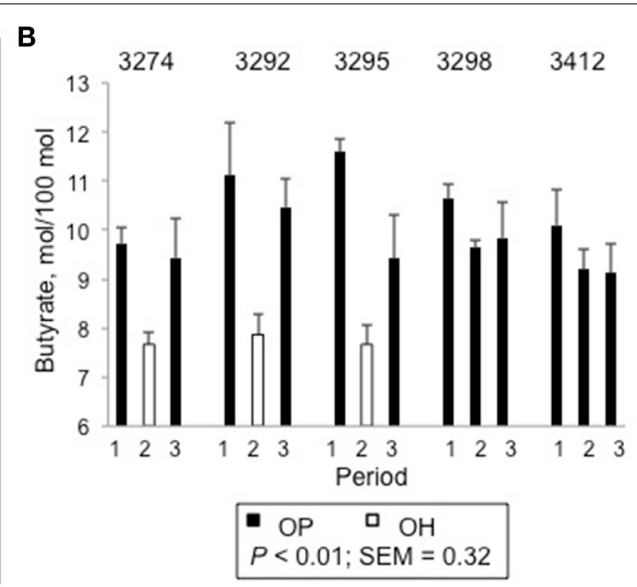

vegetative stage of growth. Comparisons reflect differences between $\mathrm{OP}$ and $\mathrm{OH}$ in heifers that received both diets. s.e.m. = standard error of the mean. were the $\mathrm{OP}$ and $\mathrm{OH}$ communities $(P<0.02)$. In addition, an OTU-based analysis of the pyrosequencing data, using averageneighbor (cutoff $=0.03$ ) rather than nearest-neighbor clustering, was performed for comparison, with effects similar to those above (Table S2).

At the phylum level, the bacterial community was dominated by members of the phylum Firmicutes, which accounted for $58-86 \%$ of the sequences in individually sequenced samples (Figure S2 and Table S3). At the genus level, Butyrivibrio was the most abundant, accounting for up to $20 \%$ of the sequences, while Prevotella accounted for 2-14\% and Ruminococcus for 2-7\% (Figure 4 and Table S4). An unexpectedly high number (58-71\%) of the sequences did not correspond to classified genera. At the genus level, only Butyrivibrio displayed significant diet-dependent shifts (Figure 4 and Table S4). In all 3 heifers receiving the OP$\mathrm{OH}-\mathrm{OP}$ treatment series, Butyrivibrio abundance decreased upon a shift from pasture to hay, and rebounded when the heifers were returned to pasture; by contrast, Butyrivibrio abundance in the two heifers retained on pasture did not show directional shifts across periods. Across animals, the least-square means for RPS of Butyrivibrio (expressed as percentage of total genus-level pyrotag sequencing reads) was higher on $\mathrm{OP}$ than on $\mathrm{OH}[13.8$ vs. $8.3 \%$, standard error of the difference $(\mathrm{SED})=1.2 \%, P=$ 0.0002 ], in accord with the higher molar proportion of butyrate on OP (Table 2 and Figure 1B). Linear regression of the RPS of genus Butyrivibrio and the molar proportion of butyrate in VFA revealed a positive correlation $(R=+0.591$ and $P=0.020$ for liquid phase RPS; $R=+0.285, P=0.304$ for solid phase RPS). By contrast, linear regression of the RPS of genus Butyrivibrio and the millimolar concentrations of butyrate did not display a significant positive correlation $(R=-0.116, P=0.680$ for liquid phase RPS, $R=-0.567, P=0.027$ for solid phase RPS). This is likely due to the poor ability of millimolar VFA concentrations to describe the ruminal fermentation and its nutritional consequences, as VFA concentrations are confounded by strong differences in ruminal volume, rate of passage and VFA uptake through the ruminal wall (Hall et al., 2014).
The observation that the bacterial community was dominated by Firmicutes, with smaller percentages of phylum Bacteroidetes and genus Prevotella, led us to quantify this genus using qRT-PCR. Both SO and L phase samples were examined, as Prevotella are known to utilize both soluble substrates and insoluble fiber and protein components of the diet. The RPS of Prevotella, expressed as a percentage of $16 \mathrm{~S}$ rRNA gene copy number detected with a genus-level primer, ranged from 16 to 34 across samples, higher than those suggested by the pyrotag sequencing. The RPS of Prevotella was significantly higher in the SO phase $(P=0.03)$ and showed a tendency $(P=0.10)$ to be different among individual heifers, but did not differ between $\mathrm{OP}$ and $\mathrm{OH}$ (Table 3 ). The RPS of two known butyrate producing taxa, the $B$. fibrisolvens group and M. elsdenii, was analyzed in L phase of rumen digesta by qPCR. For both species RPS was very low $(<0.1$ and $<0.01 \%$, respectively; Table 3 ). The RPS of $M$. elsdenii, but not the $B$. fibrisolvens group, varied among heifers, but the RPS of both taxa did not vary between the diets.

Analysis of community diversity and community richness (Table S5) revealed that community richness was not related $(P>$ 0.05 ) to dietary sequence, phase of ruminal contents (SO vs. L), or the diets (OH vs. OP). The Shannon index of community diversity was significantly higher in the L phase than the SO phase $(P<$ $0.001)$, and in the $\mathrm{OH}$ vs. $\mathrm{OP}$ community $(P=0.004)$, but the Simpson index did not differ $(P>0.05)$ within these comparison groups.

\section{DISCUSSION \\ BACTERIAL COMMUNITY COMPOSITION}

The shifts in BCC between $\mathrm{OP}$ and $\mathrm{OH}$ (evident from Figures 2, 3) occurred despite apparent similarities in their nutrient compositions (Table 1, cf. OH and OP during period 2). Although nutrient compositions were grossly similar, there may have been subtle differences between the two forms of forage with respect to physiological responses to the stresses induced by cutting and following ingestion into the rumen that may affect their susceptibility to enzymatic and microbial digestion, particularly 


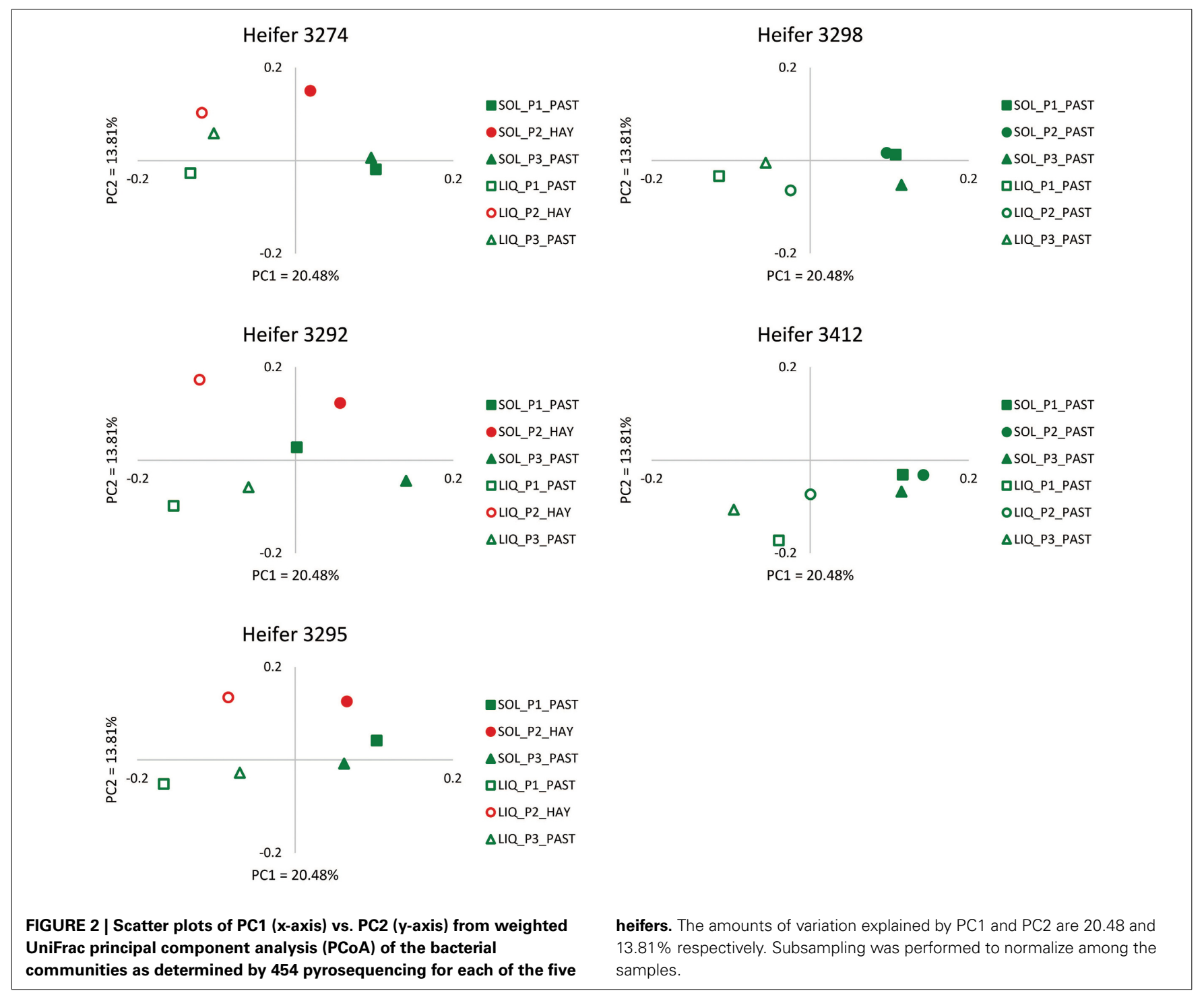

of plant protein ("accelerated induced stress," Kingston-Smith et al., 2008). The separation in the ordination points representing the $\mathrm{L}$ and SO phases of rumen digesta (Figure 3) was not as evident as that observed in our previous studies (Welkie et al., 2010; Weimer et al., 2010b; Mohammed et al., 2012). Those studies differed from the current study in that the diets offered were TMR-based diets that contained two forage sources (alfalfa and corn silages) plus grains, and several additional proteins sources, while the diets in this study were exclusively forage diets (in this case, nearly pure stands of orchardgrass). It is worth exploring the possibility that the relative proportion of SO- and L-associated bacteria could differ quantitatively between TMR and forage-only diets.

The pyrosequencing data revealed that, for all five heifers, bacteria in the phylum Firmicutes were more abundant in the rumen than were those of the Prevotellaceae (Figure S2). Previous studies employing the same primers and $\mathrm{QPCR}$ conditions have indicated that, in lactating cows fed a TMR containing alfalfa and corn silages, corn grain and protein concentrates, genus Prevotella

represented $40-60 \%$ of the $16 \mathrm{~S}$ rRNA gene copy number, as determined by qPCR (Stevenson and Weimer, 2007; Weimer et al., 2008). However, in this study, heifers fed all-forage diets (either as pasture or hay), genus Prevotella represented 16-34\%, as determined by qPCR (Table 3 ), and $<20 \%$, as determined by pyrotag sequencing (Figure 4), of the 16S rRNA gene copy number.

Although there is an abundant literature on the effect of forage:concentrate ratio on the ruminal microbiome, only a few studies have examined the bacterial community in cattle on allforage diets. Comparison of studies that used the 454 sequencing platform revealed substantial differences in ruminal community composition. For example, de Menezes et al. (2011) observed slightly higher proportions of Firmicutes than of Bacteroidetes in ruminally fistulated, lactating cows on cool-season $\mathrm{C}_{3}$ (ryegrass) pastures, while we observed somewhat higher ratios of Firmicutes to Bacterioidetes. McCann et al. (2014) examined the bacterial community in Brahman bulls from single samples collected after $60 \mathrm{~d}$ of grazing the warm season $\left(\mathrm{C}_{4}\right)$ grass, 


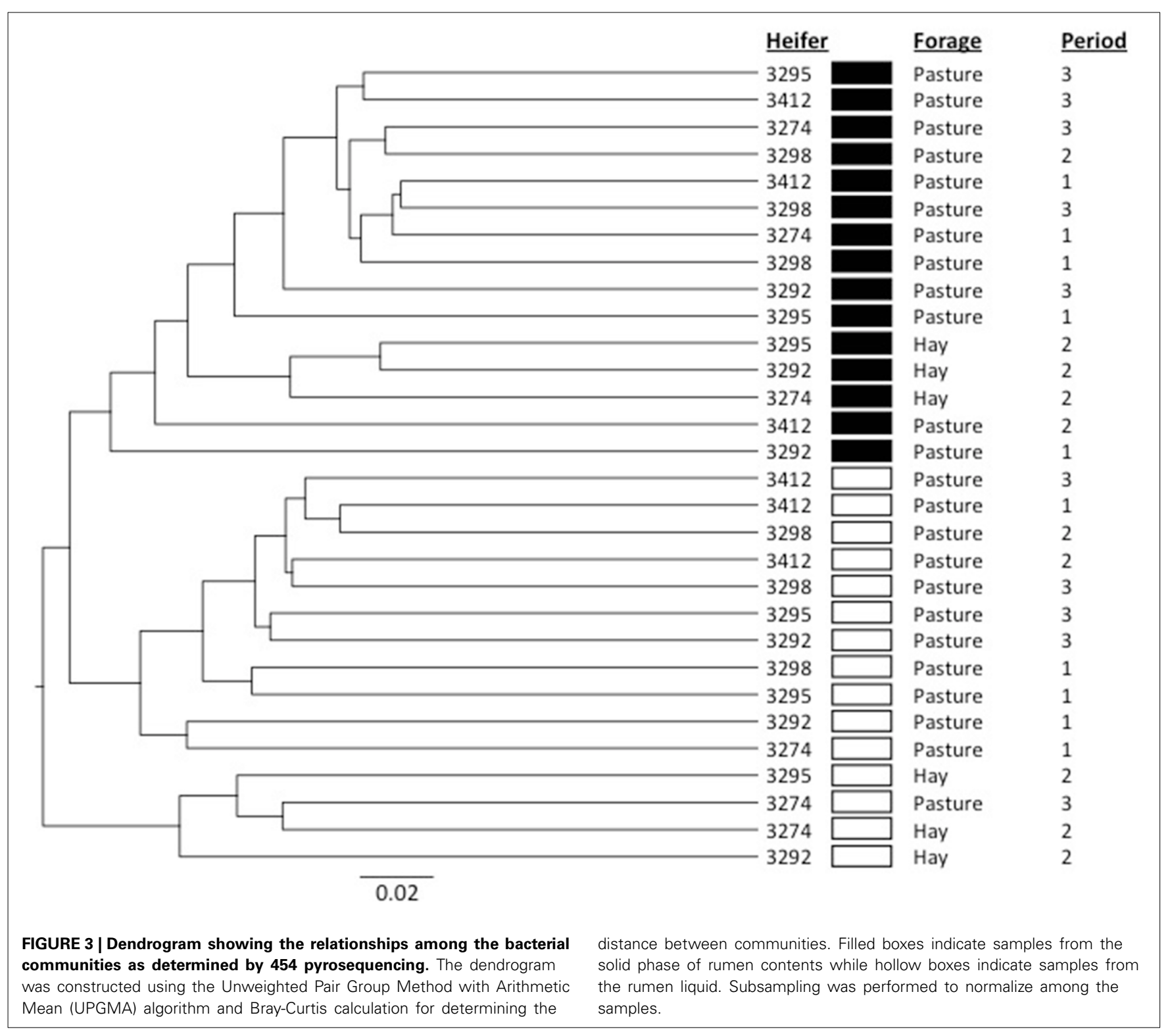

Coastal bermudagrass (Cyanodon dactylon $\mathrm{L}$ ). They reported that Bacteroidetes and Firmicutes represented 67.5 and $22.9 \%$ of the sequences at the phylum level. The substantial abundance of the Bacteroidetes could have been due to a combination of breed, forage type, collection of samples via stomach tube (which preferentially selects for planktonic cells), and the use of a commercial stool kit for DNA isolation (which results in low DNA yield and enrichment in Bacteroidetes; Henderson et al., 2013). Pitta et al. (2010) have previously demonstrated by 16S-based pyrotag sequencing that the abundance of genus Prevotella in crossbred beef steers varied with diet, and were substantially lower when the steers grazed bermudagrass than when they were switched to grazed winter wheat $(24-33 \%$ vs. $36-56 \%)$. Further research is warranted to determine the relative importance of animal type and feeding regimen on the composition of the ruminal microbiome, preferably using the same community analysis techniques across experimental conditions.

\section{RUMINAL VFA CONTENT}

The molar proportions of individual VFAs in the rumen have potential to indicate shifts in BCC, because different ruminal microbes produce different VFA products (Russell, 2002). In the present study, a greater proportion of butyrate and a lesser proportion of acetate were observed from $\mathrm{OP}$ than from $\mathrm{OH}$ when averaged across OP periods (Table 2). Although it is tempting to ascribe these differences to compositional differences (e.g., NDF and ADF contents of OP averaged across periods was higher than those of the $\mathrm{OH}$ used in period 2), the same trends in acetate and butyrate were observed within period 2 , in which $\mathrm{OH}$ and $\mathrm{OP}$ did not differ in composition (Table 1).

Differences in VFA proportions, as well as in total ruminal VFA concentration (higher for $\mathrm{OH}$ than for $\mathrm{OP}$ ) may have been related to differences in the availability of specific nutrients between $\mathrm{OP}$ and $\mathrm{OH}$, or to subtle differences in animal physiology and behavior (intake, rate of passage, and meal patterning) when 


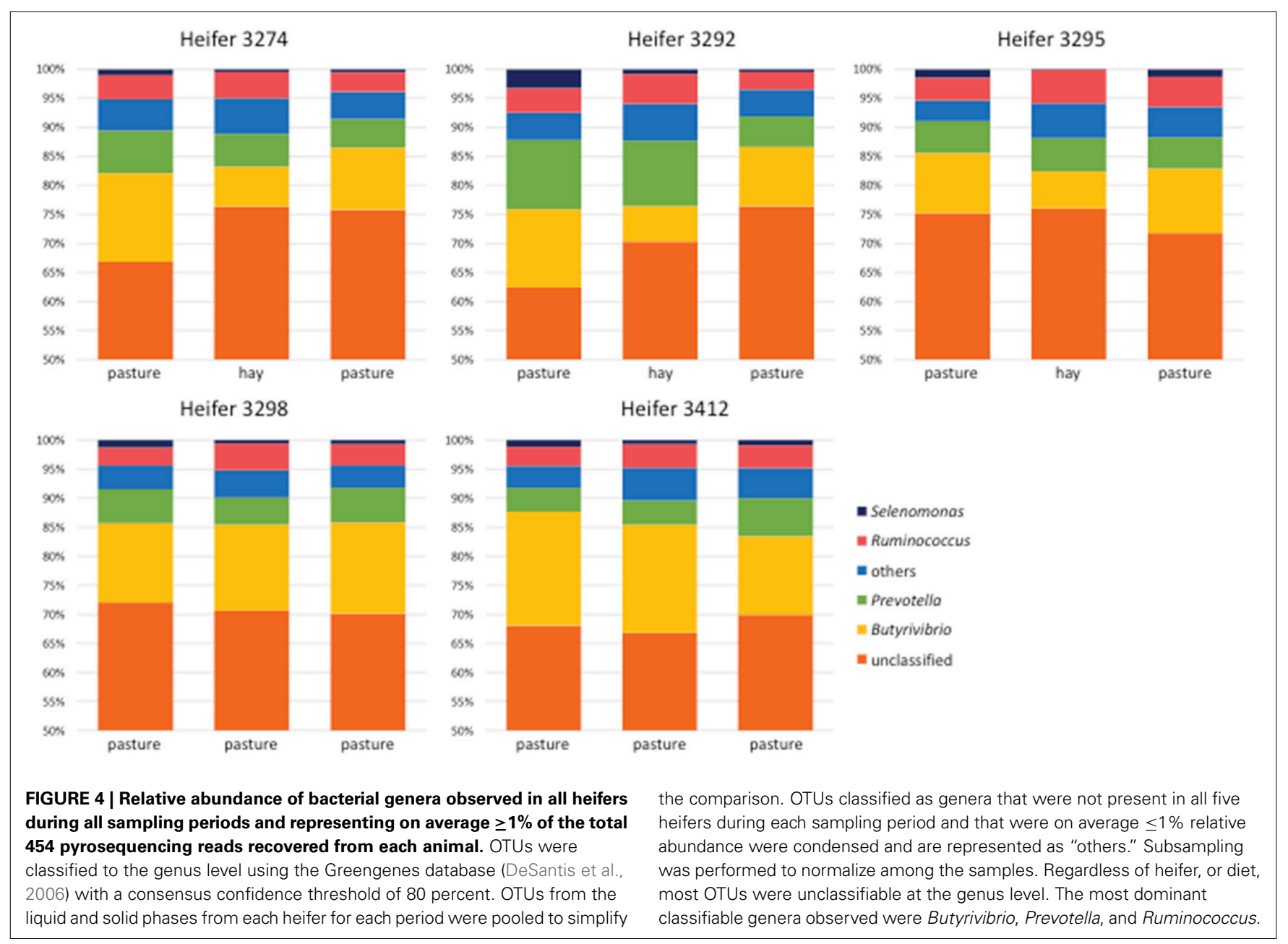

consuming $\mathrm{OP}$ vs. $\mathrm{OH}$, which were not measured in this study. Although its source remains to be identified, the greater proportion of butyrate for OP than OH reflects higher RPS of the abundant genus Butyrivibrio (Figure $\mathbf{4}$ and Table S4), which is regarded as a major ruminal butyrate producer (Miller and Jenesel, 1979). Another ruminal bacterium, M. elsdenii, is also known to produce large amounts of butyrate (Rogosa, 1971), but its relative abundance in this study was very low, and did not differ between $\mathrm{OH}$ and OP (Table 3). It is also possible that other ruminal microbes may be involved. The major butyrate producers in the rumen include several species of protozoa (Heald and Oxford, 1953; Abou Akkada and Howard, 1960; Yarlett et al., 1985), and Holden et al. (1994) reported that cows grazing primarily orchardgrass had three times higher protozoal counts than cows fed hay or silage. Huws et al. (2009), in a study comparing fresh perennial ryegrass with grass conserved as hay, found greater WSC and greater total protozoal density for fresh grass than for hay. Based on the above discussion, we speculate that the greater proportion of butyrate for $\mathrm{OP}$ than $\mathrm{OH}$ could be due to a greater population sizes of genus Butyrivibrio (Figure 4) and possibly protozoa (not tested in this study), but a connection to WSC content could not be established because WSC content did not differ between
$\mathrm{OH}$ and $\mathrm{OP}$ when both were fed over the same time period (Table 1).

The branched-chain isomers of butyric and valeric acids (collectively termed branch-chain VFA, or BCVFA) are protein degradation products resulting from the deamination of amino acids in the rumen (Russell, 2002). Greater proportions of isobutyrate and of the chromatographically co-eluting isovalerate plus 2methylbutyrate in the rumen for $\mathrm{OP}$ than $\mathrm{OH}$ are also consistent with the greater RPS of Butyrivibrio, which are also known to hydrolyze protein and ferment amino acids to ammonia and VFA (Willems and Collins, 2009), presumably including the BCVFA.

\section{CONCLUSIONS}

This study demonstrated that the small number of heifers tested displayed a statistically significant shift in BCC as they were switched from $\mathrm{OP}$ to $\mathrm{OH}$, with a decrease in the relative population size of the abundant genus Butyrivibrio on $\mathrm{OH}$ being particularly noteworthy. This shift was accompanied by, and consistent with, differences in the relative proportion of ruminal VFA (increased acetate and decreased butyrate and branched-chain VFA for $\mathrm{OH}$ relative to $\mathrm{OP}$ ). For both $\mathrm{OP}$ and $\mathrm{OH}$ treatments, the ruminal abundance of genus Prevotella was strikingly lower than 
Table 3 | Percentages of target species in rumen liquid samples relative to total eubacterial count determined by quantitative real-time PCR analysis in heifers grazing orchargrass pasture (OP) or consuming orchardgrass hay (OH) diets ${ }^{\mathrm{a}}$.

\begin{tabular}{|c|c|c|c|c|c|c|c|c|c|c|c|c|c|c|c|}
\hline \multirow[t]{3}{*}{ Species1 } & \multirow{3}{*}{ Phase } & \multicolumn{4}{|c|}{ Diet } & \multicolumn{10}{|c|}{ Heifer x Diet } \\
\hline & & \multirow[t]{2}{*}{ Hay } & \multirow[t]{2}{*}{ Pasture } & \multirow[t]{2}{*}{ s.e.m. } & \multirow[t]{2}{*}{$P$-value } & \multicolumn{2}{|c|}{3274} & \multicolumn{2}{|c|}{3292} & \multicolumn{2}{|c|}{3295} & \multirow{2}{*}{$\frac{3298}{\text { Pasture }}$} & \multirow{2}{*}{$\frac{3412}{\text { Pasture }}$} & \multirow[t]{2}{*}{ s.e.m. } & \multirow[t]{2}{*}{$P$-value } \\
\hline & & & & & & Hay & Pasture & Hay & Pasture & Hay & Pasture & & & & \\
\hline M. elsdenii & Liquid & 0.001 & 0.003 & 0.001 & 0.21 & 0.001 & 0.001 & 0.001 & 0.004 & 0.001 & 0.002 & 0.003 & 0.007 & 0.002 & 0.39 \\
\hline B. fibrisolvens & Liquid & 0.081 & 0.060 & 0.017 & 0.36 & 0.084 & 0.041 & 0.098 & 0.067 & 0.057 & 0.053 & 0.059 & 0.054 & 0.031 & 0.97 \\
\hline Prevotella & Solid & 25.0 & 24.7 & 2.39 & 0.94 & 18.0 & 24.0 & 29.0 & 32.0 & 28.0 & 21.5 & 21.0 & 25.0 & 4.69 & 0.35 \\
\hline Prevotella & Liquid & 33.7 & 23.9 & 3.07 & 0.07 & $17.0 \mathrm{~b}$ & $30.5 b$ & $68.0 a$ & $26.0 \mathrm{~b}$ & $16.0 \mathrm{~b}$ & $23.0 b$ & $19.7 b$ & $20.7 b$ & 5.53 & 0.01 \\
\hline
\end{tabular}

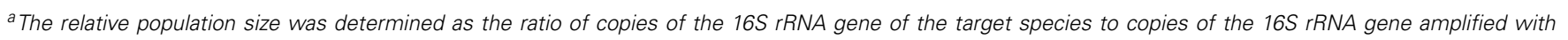
eubacterial primers and expressed as percentage.

has been widely observed in cows fed a TMR of forages, grain and protein concentrates.

\section{AUTHOR CONTRIBUTIONS}

Conceived and designed the experiments: Geoffrey E. Brink, Paul J. Weimer, Riazuddin Mohammed, Karen A. Beauchemin. Performed the experiments: Riazuddin Mohammed, Geoffrey E. Brink, David M. Stevenson, Anthony P. Neumann, Paul J. Weimer. Analyzed the data: Riazuddin Mohammed, David M. Stevenson, Geoffrey E. Brink, Anthony P. Neumann, Garret Suen, Paul J. Weimer. Contributed reagents/materials/analysis tools: Geoffrey E. Brink, Paul J. Weimer, David M. Stevenson, Garret Suen, Karen A. Beauchemin. Wrote the paper: Riazuddin Mohammed, Paul J. Weimer, Geoffrey E. Brink. All authors agree to be accountable for all aspects of the work.

\section{ACKNOWLEDGMENTS}

We thank J. Bleier (USDFRC; Madison, WI) for maintaining pastures and for animal feeding and handling; M. Maroney (UW) for rumen cannulation surgeries; C.L. Odt (USDFRC) for HPLC analysis; K.A. Jewell for sequencing and analysis help; and M.B. Hall for helpful discussions. This research was supported by USDA Agricultural Research Service through CRIS project 3655-21000-024-00D and by Agriculture and Agri-Food Canada.

\section{SUPPLEMENTARY MATERIAL}

The Supplementary Material for this article can be found online at: http://www.frontiersin.org/journal/10.3389/fmicb. 2014.00689/abstract

\section{REFERENCES}

Abou Akkada, A. R., and Howard, B. (1960). The biochemistry of rumen protozoa. 3. The carbohydrate metabolism of Entodinium. Biochem. J. 76, 445-451.

Boeckaert, C., Vlaeminck, B., Fievez, V., Maignien, L., Dijkstra, J., and Boon, N. (2008). Accumulation of trans C-18:1 fatty acids in the rumen after dietary algal supplementation is associated with changes in the Butyrivibrio community. Appl. Environ. Microbiol. 74, 6923-6930. doi: 10.1128/AEM.01473-08

Brink, G. E., and Casler, M. D. (2012). Yield and nutritive value differences among cool-season grasses. Forage Grazinglands. doi: 10.1094/FG-2012-0619-01-RS

Brink, G. E., Jackson, R. D., and Alber, N. B. (2013). Residual sward height effects on growth and nutritive value of grazed temperate perennial grasses. Crop Sci. 53, 1-11. doi: 10.2135/cropsci2013.01.0068
Cardinale, M., Brusetti, L., Quatrini, P., Borin, S., Puglia, A. M., Rizzi, A., et al. (2004). Comparison of different primer sets for use in automated ribosomal intergenic spacer analysis of complex bacterial communities. Appl. Environ. Microbiol. 70, 6147-6156. doi: 10.1128/AEM.70.10.61476156.2004

Clarke, K. R. (1993). Non-parametric multivariate analyses of changes in community structure. Austr. J. Ecol. 18, 117-143. doi: 10.1111/j.1442-9993

Dehority, B. A. (2003). "Numbers, factors affecting the population and distribution of rumen bacteria," in Rumen Microbiology, ed B. A. Dehority (Nottingham: Nottingham University Press), 265-294.

Dehority, B. A., and Orpin, C. G. (1997). "Development of, and natural fluctuations in, rumen microbial populations," in The Rumen Microbial Ecosystem, 2nd Edn., eds P. N. Hobson and C. S. Stewart (London: Blackie Academic and Professional), 196-245.

de Menezes, A. B., Lewis, E., O’Donovan, M., O’Neill, B. F., Clipson, N., and Doyle, E. M. (2011). Microbiome analysis of dairy cows fed pasture or total mixed ration diets. FEMS Microbiol. Ecol. 78, 256-265. doi: 10.1111/j.15746941.2011.01151.x

DeSantis, T. Z., Hugenholtz, P., Larsen, N., Rojas, M., Brodie, E. L., Keller, K., et al. (2006). Greengenes, a chimera-checked 16S rRNA gene database and workbench compatible with ARB. Appl. Environ. Microbiol. 72, 5069-5072. doi: 10.1128/AEM.03006-05

Dubois, M., Gilles, K. A., Hamilton, J. K., Rebers, P. A., and Smith, F. (1956). Colorimetric method for determination of sugars and related substances. Anal. Chem. 28, 350-356.

Good, I. (1953). The population frequencies of species and the estimation of population parameters. Biometrika 30, 237-264.

Hall, M. B., Nennich, T. D., and Doane, P. H. (2014). Total volatile fatty acid concentrations are unreliable estimates of treatment effects on in vivo ruminal fermentation. J. Dairy Sci. 97(E-Suppl. 1), 302.

Heald, P. J., and Oxford, A. E. (1953). Fermentation of soluble sugars by anaerobic holotrich ciliate protozoa of the genera Isotricha and Dasytricha. Biochem. J. 53, 506-512.

Henderson, G., Cox, C., Kittelmann, S., Miri, V. H., Zethof, M., Noel, S. J., et al. (2013). Effect of DNA extraction methods and sampling techniques on the apparent structure of cow and sheep rumen microbial communities. PLoS ONE 8:e74787. doi: 10.1371/journal.pone.0074787

Holden, L. A., Muller, L. D., Varga, G. A., and Hillard, P. J. (1994). Ruminal digestion and duodenal nutrient flows in dairy cows consuming grass as pasture, hay or silage. J. Dairy Sci. 77, 3034-3042.

Huws, S. A., Kim, E. J., Kingston-Smith, A. H., Lee, M. R. F., Muetzel, S. M., Cookson, A. R., et al. (2009). Rumen protozoa are rich in polyunsaturated fatty acids due to the ingestion of chloroplasts. FEMS Microbiol. Ecol. 69, 461-471. doi: 10.1111/j.1574-6941.2009.00717.x

Kim, E. J., Huws, S. A., Lee, M. R. F., Wood, J. D., Muetzel, S. M., Wallace, R. J., et al. (2008). Fish oil increases the duodenal flow of long chain polyunsaturated fatty acids and trans-11 18:1 and decreases 18:0 in steers via changes in the rumen bacterial community. J. Nutr. 138, 889-896.

Kingston-Smith, A. H., Davies, T. E., Edwards, J. E., and Theodorou, M. K. (2008). From plants to animals; the role of plant cell death in ruminant herbivores. J. Exp. Bot. 59, 521-532. doi: 10.1093/jxb/erm326 
Lozupone, C., and Knight, R. (2005). UniFrac: a new phylogenetic method for comparing microbial communities. Appl. Environ. Microbiol. 71, 8228-8235. doi: 10.1128/AEM.71.12.8228-8235.2005

Ludwig, J. A., and Reynolds, J. F. (1988). Statistical Ecology. New York, NY: John Wiley and Sons.

McCann, J. C., Wiley, L. M., Forbes, T. D., Rouquette, F. M. Jr., and Tedeschi, L. O. (2014). Relationship between the rumen microbiome and residual feed intake-efficiency of Brahman bulls stocked on Bermudagrass pastures. PLoS ONE 9:e91864. doi: 10.1371/journal.pone.0091864

Mertens, D. R. (2002). Gravimetric determination of amylase-treated neutral detergent fiber in feeds with refluxing in beakers or crucibles: collaborative study. J. AOAC Int. 85, 1217-1240.

Miller, T. L., and Jenesel, S. E. (1979). Enzymology of butyrate formation by Butyrivibrio fibrisolvens. J. Bacteriol. 138, 99-104.

Mohammed, R., Stevenson, D. M., Beauchemin, K., Weimer, P. J., and Muck, R. E. (2012). Changes in ruminal bacterial community composition following feeding of alfalfa silage inoculated with a commercial silage inoculant. J. Dairy Sci. 95, 328-339. doi: 10.3168/jds.2011-4492

Moore, K. J., Moser, L. E., Vogel, K. P., Waller, S. S., Johnson, B. E., and Pedersen, J. F. (1991). Describing and quantifying growth stages of perennial forage grass. Agron. J. 83, 1073-1077.

Pitta, D. W., Kumar, S., Veiccharelli, B., Parmar, N., Reddy, B., and Joshi, C. G. (2014). Bacterial diversity associated with feeding dry forage at different dietary concentrations in the rumen contents of Mehshana buffalo (Bubalis bubalis) using 16S pyrotags. Anaerobe 25, 31-41. doi: 10.1016/j.anaerobe.2013.11.008

Pitta, D. W., Pinchak, W. E., Dowd, S. E., Osterstock, J., Gontcharova, V., Youn, E., et al. (2010). Rumen bacterial diversity dynamics associated with changing bermudagrass hay to grazed winter wheat diets. Microb. Ecol. 59, 511-522. doi: 10.1007/s00248-009-9609-6

Pruesse, E., Quast, C., Knittel, K., Fuchs, B. M., Ludwig, W., Peplies, J., et al. (2007). SILVA: a comprehensive online resource for quality checked and aligned ribosomal RNA sequence data compatible with ARB. Nucleic Acids Res. 35, 7188-7196. doi: 10.1093/nar/gkm864

Quince, C., Lanzen, A., Davenport, R. J., and Turnbaugh, P. J. (2011). Removing noise from pyrosequenced amplicons. BMC Bioinformatics 12:38. doi: 10.1186/1471-2105-12-38

Rogosa, M. (1971). Transfer of Peptostreptococcus elsdenii Gutierrez et al. to a new genus, Megapshaera [M. elsdenii (Gutierrez et al.) comb nov.] Int. J. Syst. Bacteriol. 21, 187-189. doi: 10.1099/00207713-21-2-187

Russell, J. B. (2002). Rumen Microbiology and its Role in Ruminant Nutrition. Ithaca, NY: James B. Russell Publishing. Available online at: http://www.ars.usda.gov/ services/software/download.htm?softwareid $=409$

Schloss, P. D., Westcott, S. L., Ryabin, T., Hall, J. R., Hartmann, M., Hollister, E. B., et al. (2009). Introducing mothur: open-source, platform-independent, community-supported software for describing and comparing microbial communities. Appl. Environ. Microbiol. 75, 7537-7541. doi: 10.1128/AEM.01541-09

Stevenson, D. M., and Weimer, P. J. (2007). Dominance of Prevotella and low abundance of classical ruminal bacterial species in the bovine rumen revealed by relative quantification real-time PCR. Appl. Microbiol. Biotechnol. 75, 165-174. doi: 10.1007/s00253-006-0802-y
Van Soest, P. J., Robertson, J. B., and Lewis, B. A. (1991). Methods for dietary fiber, neutral detergent fiber, and nonstarch polysaccharides in relation to animal nutrition. J. Dairy Sci. 74, 3583-3597.

Weimer, P. J., Shi, Y., and Odt, C. L. (1991). A segmented gas/liquid delivery system for continuous culture of microorganisms on solid substrates, and its use for growth of Ruminococcus flavefaciens on cellulose. Appl. Microbiol. Biotechnol. 36, 178-183. doi: 10.1007/BF00164416

Weimer, P. J., Stevenson, D. M., Mantovani, H. C., and Man, S. L. C. (2010a). Host specificity of the ruminal bacterial community of the dairy cow following near-total exchange of ruminal contents. J. Dairy Sci. 93, 5902-5912. doi: 10.3168/jds.2010-3500

Weimer, P. J., Stevenson, D. M., and Mertens, D. R. (2010b). Shifts in bacterial community composition in the rumen of lactating dairy cows under milk fat-depressing conditions. J. Dairy Sci. 93, 265-278. doi: 10.3168/jds.2009-2206

Weimer, P. J., Stevenson, D. M., Mertens, D. R., and Thomas, E. E. (2008). Effect of monensin feeding and withdrawal on populations of individual bacterial species in the rumen of lactating dairy cows fed high-starch rations. Appl. Microbiol. Biotechnol. 80, 135-145. doi: 10.1007/s00253-008-1528-9

Welkie, D. G., Stevenson, D. M., and Weimer, P. J. (2010). ARISA analysis of ruminal bacterial community dynamics in lactating dairy cows during the feeding cycle. Anaerobe 16, 94-100. doi: 10.1016/j.anaerobe.2009.07.002

Willems, A., and Collins, M. D. (2009). "Genus V, Bryant and Small 1956b, 18 emend Moore, Johnson and Holdemann 1976, 241 ${ }^{\mathrm{AL}}$," in Bergey's Manual of Systematic Bacteriology, 2nd Edn., Vol. 3. The Firmicutes, eds P. Vos, G. Garrity, D. Jones, N. R. Krieg, W. Ludwig, et al. (Dordrecht: Springer), 927-938.

Yarlett, N., Lloyd, D., and Williams, A. G. (1985). Butyrate formation from glucose by the rumen protozoan Dasytricha ruminantium. Biochem. J. 228, 187-192.

Yu, Y., Lee, C., Kim, J., and Hwang, S. (2005). Group-specific primer and probe sets to detect methanogenic communities using quantitative real-time polymerase chain reaction. Biotechnol. Bioeng. 89, 670-679. doi: 10.1002/bit.20347

Conflict of Interest Statement: The authors declare that the research was conducted in the absence of any commercial or financial relationships that could be construed as a potential conflict of interest.

Received: 15 August 2014; accepted: 21 November 2014; published online: 09 December 2014.

Citation: Mohammed R, Brink GE, Stevenson DM, Neumann AP, Beauchemin KA, Suen $G$ and Weimer PJ (2014) Bacterial communities in the rumen of Holstein heifers differ when fed orchardgrass as pasture vs. hay. Front. Microbiol. 5:689. doi: 10.3389/ fmicb.2014.00689

This article was submitted to Systems Microbiology, a section of the journal Frontiers in Microbiology.

Copyright (c) 2014 Mohammed, Brink, Stevenson, Neumann, Beauchemin, Suen and Weimer. This is an open-access article distributed under the terms of the Creative Commons Attribution License (CC BY). The use, distribution or reproduction in other forums is permitted, provided the original author(s) or licensor are credited and that the original publication in this journal is cited, in accordance with accepted academic practice. No use, distribution or reproduction is permitted which does not comply with these terms. 